Удк 661.728.87:661.728.21.08

\title{
ВЛИЯНИЕ РАСПОЛОЖЕНИЯ СУЛЬФАТНЫХ ГРУПП В СУЛЬФАТАХ ЦЕЛЛЮЛОЗЫ НА СТАБИЛЬНОСТЬ ИХ МАКРОМОЛЕКУЛЫ
}

\author{
(C) Н.С. Нормахаматов", К.М. Чуркина, А.С. Тураев \\ Институт биоорганической химии Академии наук Республики Узбекистан, \\ ул. М. Улугбека, 83, Ташкент, 100125 (Узбекистан), e-mail: nodirali@gmail.com
}

\begin{abstract}
Приведены результаты исследования по получению образцов натриевых солей сульфатов целлюлозы (Na-CЦ) из хлопковой целлюлозы с различными молекулярными параметрами и изучено влияния расположения сульфатных групп в ангидроглюкопиранозной единице (АГЕ) на стабильность макромолекулы. Рассмотрено изменение молекулярных параметров образцов при хранении их водных растворов в течение определенного времени. Методом термогравиметрического анализа и дифференциальной калориметрии определена стабильность образцов в сухом виде. Показано, что образцы с высокой степенью замещения (С3) обладают высокой стабильностью, а сульфатпроизводные образцы, имеющие замещенную сульфатную группу на 3-углеродном атоме, обладают самой низкой стабильностью. Предположительно, причиной нестабильности является присутствие транс-гидроксильных групп в макромолекуле.

Ключевые слова: натриевая соль сульфата целлюлозы, расположение замещенных групп, стабильность макромолекулы, термогравиметрия.
\end{abstract}

\section{Введение}

Сернокислые эфиры целлюлозы проявляют антитромболитическую, противопаразитную, антивирусную, антимикробную, ВИЧ ингибирующую, противоопухолевую и иммуномодулирующую активности [1-4].

Сульфаты полисахаридов в кислотной форме, т.е. в форме полисахарид- $\mathrm{SO}_{3} \mathrm{H}$, особенно при высоких степенях замещения (С3), неустойчивы, так как в присутствии даже незначительных следов воды идет диссоциация, и образуются $\mathrm{H}^{+}$и $-\mathrm{SO}_{3}{ }^{2-}$ ионы, вследствие чего происходит процесс гидролитического расщепления макромолекулы полисахарида. Хотя натриевые соли сульфатов полисахаридов стабильнее, чем их кислотные формы, они также подвергаются гидролизу и деструкции при высокой температуре и влажности, что нежелательно при использовании их в медицине и фармакологии [5-8].

Цель данного исследования заключалась в получении сульфатпроизводных полисахаридов (целлюлозы и полигалактуроновой кислоты) и в изучении влияния расположения сульфатных групп на стабильность их макромолекулы.

\section{Экспериментальная часть}

В качестве сырья при сульфатировании использовали волокнистую хлопковую целлюлозу со $\mathrm{C} \Pi=1400$ и влажностью $10 \%$.

Нормахаматов Нодирали Сохобаталиевич - старший научный сотрудник, кандидат химических наук, тел.: (+99871) 262-35-40, факс: (+99871) 262-70-63, e-mail: nodirali@gmail.com

Чуркина Ксения Михайловна - младший научный сотрудник, тел.: (+99871) 262-35-40, факс: (+99871) 262-70-63, e-mail: kseniya08@mail.ru Тураев Аббасхан Сабирханович - ведущий научный сотрудник, доктор химических наук, профессор, тел.: (+99871) 262-35-40, факс: (+99871) 262-70-63, e-mail: abbaskhan@mail.ru
Полигалактуроновая кислота для сульфатирования получена диметоксилированием цитрусового пектина по методике [9]. Полученную полигалактуроновую кислоту анализировали ИК-спектроскопическим методом, количество возможных остаточных метоксильных групп определяли по методу [10].

Синтез сульфатов полисахаридов проводили различными методами: моно- и дисульфат целлюло-

\footnotetext{
* Автор, с которым следует вести переписку.
} 
зы (с расположением сульфатных групп у 2-го, и/или 3-го, и/или 6-го углеродных атомов соответственно: $\{\mathrm{C}-2\},\{\mathrm{C}-3\},\{\mathrm{C}-6\}$ и $\{\mathrm{C}-2,3\})$ были получены методами избирательного сульфатирования $[11,12]$ и могут быть кратко описаны следующим образом.

Получение образиов моносульфатов иеллюлозы с расположением замещенных групп у 3-го углеродного атома ангидропиранозной единицы (AГE) \{C-3\}. В качестве протекторов при избирательном сульфатировании использовали трифторацетатные группы [13]. При действии на целлюлозу смесью трифторуксусного ангидрида и трифторуксусной кислоты при $25^{\circ} \mathrm{C}$ в течение 4 ч получается дитрифторацетат целлюлозы с расположением замещенных групп преимущественно у 6-го и 2-го атомов углерода. Далее, сульфатируя этот образец комплексом $\mathrm{SO}_{3}$-пиридин при $15^{\circ} \mathrm{C}$ с последующей нейтрализацией $\mathrm{NaOH}$, получали образец натриевой соли сульфата целлюлозы (Na-CЦ) с $\mathrm{C} 3$ 0,97. Методом газожидкостной хроматографии (ГЖХ) установлено, что замещение сульфогруппами происходит преимущественно у 3-го углеродного атома $(87,2 \%)$. Замещение гидроксильных групп происходит по схеме $\{\mathrm{O}-3\}>>\{\mathrm{O}-6\}>\{\mathrm{O}-2\}>\{\mathrm{O}-3,6\}>$ $\{\mathrm{O}-2,3\}=\{\mathrm{O}-2,6\}>\{\mathrm{O}-2,3,6\}[14]$.

Получение образиов сульфатов иеллюлозы с расположением замещенных групп у 6-го углеродного атома АГЕ \{C-6\}. 5 г хлопкового линта суспензировали в 250 мл сухого диметилформамида (ДМФА). Затем добавляли 9 г уксусного ангидрида и 7 г хлоросульфоновой кислоты. Реакционную смесь перемешивали в течение 8 ч при $50{ }^{\circ} \mathrm{C}$. После окончания реакции смесь нейтрализовали этанолом, содержащим ацетат натрия. Продукт промывали 70-80\%-ным спиртом. Затем полученный смешанный эфир ацетатсульфат целлюлозы суспензировали в 4\%-ном растворе $\mathrm{NaOH}$ и перемешивали в течение 1 ч при комнатной температуре. Суспензию оставляли на 15 ч для полного дезацетилирования с последующим осаждением и промыванием этанолом. $\mathrm{pH}$ раствора доводится до $\mathrm{pH}=7,5-8$ уксусной кислотой, для получения натриевой соли сернокислого эфира целлюлозы. Конечный продукт промывали этанолом и высушили при $50{ }^{\circ} \mathrm{C}$.

Альтернативно моносульфат целлюлозы $\{\mathrm{C}-6\}$ синтезировали бинарным способом сульфатирования с помощью смеси концентрированной серной кислоты и алифатического спирта (метанол, этанол, изопропанол) в течение 3 ч [11]. Очистку продукта осуществляли так же, как и в вышеперечисленных методах. Результаты показали, что образцы имели С3 0,91 и 0,98 соответственно и содержали монозамещенные звенья, у которых сульфатные группы расположены в основном при 6-м углеродном атоме АГЕ $(89,2 \%)$.

Получение образиов дисульфатов целлюлозы с расположением замещенных групп у 2-го и 3-го углеродных атомов $A Г E\{C-2,3\}$. Для синтеза использовали коммерческий ацетат целлюлозы со степенью замещения 2,9. Триацетат целлюлозы был подвергнут омылению с использованием гексаметилендиамина в среде ДМФА. Реакцию проводили при повышенной температуре в течение 10 ч при мольном соотношении триацетат целлюлозы : гексаметилендиамин в пределе $1: 1-4$. Полученный моноацетат целлюлозы был сульфатирован хлорсульфоновой кислотой в пиридине при $60-80^{\circ} \mathrm{C}$ в течение $1-4$ ч. В ходе реакции сульфатирования на первом этапе образуется смешанный эфир ацетатсульфат целлюлозы, у которого сульфатные группы расположены преимущественно у 2-го углеродного атома $(\mathrm{C} 3=0,92$ и расположение сульфатных групп у С-2 в АГЕ 86,6\%), в ходе дальнейшего сульфатирования образуются дизамещенные образцы с расположением замещенных групп у 2,3 углеродных атомов (C3=1,92, расположение в $\mathrm{C}-2,3$ у АГЕ $82,7 \%)$. Полученные образцы при нейтрализации подвергают полному дезацетилированию раствором гидроксида натрия.

Получение образиов трисульфатов целлюлозы $\{C-2,3,6\}$. Синтез трисульфата целлюлозы $\{\mathrm{C}-2,3,6\}$ проводили комплексом $\mathrm{SO}_{3}$-пиридин с предварительной активацией хлопковой целлюлозы $[1,11]$.

В трехгорловой колбе к безводному пиридину добавляли по каплям хлорсульфоновую кислоту при мольном соотношении $3,56: 1$ и при $-10^{\circ} \mathrm{C}$. Далее в реакционную смесь помещали предварительно высушенную целлюлозу. Синтез проводится при $+75^{\circ} \mathrm{C}$ в течение 4 ч. По окончании реакции из реакционной массы отфильтровывали избыточное количество пиридина, высасывая вакуумом в фильтре Шота. Фильтрат промывали этанолом, а затем ацетоном несколько раз. Полученную волокнистую массу подвергали нейтрализации добавлением насыщенного водного раствора бикарбоната натрия до $\mathrm{pH}$ среды, равной 8,0. Далее массу растворяли в водно-щелочном растворе и оставляли при комнатной температуре в течение 12 ч. Раствор подвергали диализу через диализную мембрану до отрицательной реакции на ионы $-\mathrm{SO}_{4}{ }^{2-}$ в диализате. Диализованный прозрачный раствор продукта высушивали на роторном испарителе. С3 продукта 2,86 и расположения замещенных групп у 2,3,6-углеродных атомов равны 85,2\% по результатам ГЖХ. 
Полигалактуроновую кислоту (содержание остаточных метоксильных групп < 1,3\%) активировали смесью ледяной уксусной кислоты и пиридина и дальнейшее сульфатирование проводили комплексом $\mathrm{SO}_{3}-$ пиридин по вышеуказанному способу сульфатирования целлюлозы с учетом мольного соотношения реагирующих веществ, в результате получен образец сульфата полигалактуроновой кислоты (СПГК) со C3-so3Na $=2,76$.

C3 сульфатов полисахаридов вычисляли по содержанию серы, которую определяли гравиметрическим методом по ГОСТ 93-2002. Распределение замещенных групп проводили методом газожидкостной хроматографии по Хакамори [14]. Метилированные образцы (2 мг) гидролизовали 2-3 ч 2М трифторуксусной кислотой при $120{ }^{\circ} \mathrm{C}$. После нейтрализации смесь восстанавливали $\mathrm{NaBH}_{4}(4$ мг) и ацетилировали уксусным ангидридом в пиридине. Частично метилированные ацетаты сахаридов анализировали с помощью ГЖХ. Характеристическую вязкость [ๆ] растворов сульфатов целлюлозы измеряли в 1\%-ном водном растворе $\mathrm{NaCl}$ на вискозиметре Убеллоде $(\mathrm{d}=0,6 \mathrm{mм})$ при температуре $+25^{\circ} \mathrm{C}\left( \pm 0,1^{\circ} \mathrm{C}\right)$. ИК-спектры сняты на Brücker Tensor 27 спектрометре (в диапазоне 400-4000 cm $\mathrm{cm}^{-1}$ ) методом Diamant-ATR. Термоаналитические исследования были проведены на ТГ-ДСК-анализаторе STA-409 PG фирмы NETZSCH (Германия), оснащенном термопарой типа К (Low RG Silver), с использованием алюминиевых тиглей. Количество образца составляло в пределах 3-5 мг. Все измерения проводились в инертной атмосфере азота со скоростью продувки 50 мл/мин. Температурный диапазон измерений составлял 20-400 ${ }^{\circ} \mathrm{C}$ при скорости нагрева $5 \mathrm{~K} /$ мин. Измерительная система была откалибрована с использованием стандартных веществ - индий, висмут, олово, цинк, и хлорид цезия.

Растворы Na-СЦ для изучения их стабильности при хранении стерилизовали фильтрованием с помощью мембранных фильтров, задерживающих микроорганизмы и их споры. Размер пор стерилизующего мембранного фильтра 0,3 мкм. Фильтрование проводили при положительном давлении (до 0,7 МПа).

\section{Обсуждение результатов}

Макромолекулы исследуемых водорастворимых образцов $\mathrm{Na-CЦ,} \mathrm{синтезированных} \mathrm{вышеперечис-}$ ленными методами, состоят из статистически чередующихся $\alpha(1 \rightarrow 4)$-связанных остатков сульфатированных ангидроглюкопиранозных единиц. В ИК-спектрах сульфатированных образцов наблюдаются спектральные поглощения в областях 1240 и 800-820 см-1, свойственные соответственно $\mathrm{S}=\mathrm{O}$ и $\mathrm{C}-\mathrm{O}-\mathrm{S}$ связям, которые доказывают образование сложных эфиров сульфатов полисахаридов.

С целью определения параметров, действующих на устойчивость Na-СЦ, изучены их растворы в течение одного года при комнатной температуре (табл.). Исходя из С3 образцов Na-СЦ их растворы проявили различную стабильность. Показано, что растворы Na-СЦ со С3 больше 1,5 более устойчивы во времени, их [ๆ] понижается на 66,7\% от своих начальных значений, а растворы Na-СЦ со С3 больше 2,5, незначи-

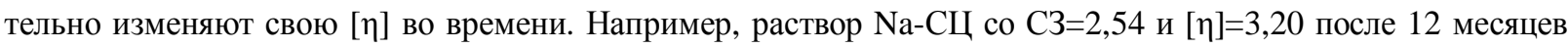
характеризуется значением $[\eta]=2,78$ (уменьшается на 13\%), а раствор Na-СЦ со С3 =1,82 и [ๆ]=1,86 через год имеет $[\eta]=0,98$ (уменьшается на 47,3\%)

Результаты определения изменений [ๆ] растворов Na-СЦ в зависимости от продолжительности хранения

\begin{tabular}{|c|c|c|c|c|c|c|}
\hline \multirow{2}{*}{ № } & \multirow{2}{*}{ C3 } & \multirow{2}{*}[\eta]{$_{\text {нач. }}$} & \multicolumn{4}{|c|}{ 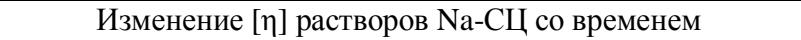 } \\
\hline & & & 2 мес. & $4 \mathrm{mec}$. & 6 мес. & $12 \mathrm{мес}$. \\
\hline 1 & 0,17 & 1,62 & 1,58 & 1,45 & $-^{*}$ & $-^{*}$ \\
\hline 2 & 0,46 & 1,37 & 1,27 & 1,16 & 0,93 & -* \\
\hline 3 & 0,67 & 1,72 & 1,54 & 1,23 & 1,15 & 0,25 \\
\hline 4 & 0,82 & 1,84 & 1,62 & 1,37 & 1,10 & 0,37 \\
\hline 5 & 1,14 & 1,77 & 1,66 & 1,32 & 1,22 & 0,44 \\
\hline 6 & 1,38 & 2,66 & 2,44 & 2,34 & 1,77 & 1,11 \\
\hline 7 & 1,57 & 2,24 & 2,10 & 1,77 & 1,05 & 0,56 \\
\hline 8 & 1,82 & 1,86 & 1,68 & 1,46 & 1,28 & 0,98 \\
\hline 9 & 2,10 & 1,90 & 1,72 & 1,56 & 1,24 & 1,12 \\
\hline 10 & 2,25 & 2,20 & 2,08 & 1,88 & 1,64 & 1,25 \\
\hline 11 & 2,40 & 2,56 & 2,38 & 2,13 & 2,07 & 1,56 \\
\hline 12 & 2,66 & 2,12 & 2,04 & 1,92 & 1,78 & 1,62 \\
\hline 13 & 2,54 & 3,20 & 3,16 & 3,10 & 3,07 & 2,78 \\
\hline
\end{tabular}

* Появилось помутнение; [ๆ] нач. - начальная вязкость растворов. 
Этот эффект можно объяснить результатами исследования Персиваля [15] по влиянию щелочной среды на стабильность сульфатов целлюлозы с низкой и высокой степенями замещения. Однако в этом исследовании не приводятся результаты по расположению сульфатных групп в ангидроглюкопиранозной единице и их влиянию на стабильность макромолекулы.

Образцы со С3 более чем 2, возможно, содержат ди- и тризамещенные остатки, и их стабильность, вероятно, объясняется высоким отрицательным зарядом, который отражают гидроксильные ионы. Образцы со С3 до 2 содержат моно- и дизамещенные единицы, и их сульфатные группы легко отщепляются в присутствии соседних транс-гидроксильных групп (при С-3 и С-6). Однако некоторые образцы (образцы 6 и 7) ведут себя по-другому: несмотря на относительно большое значение С3, значение [ๆ] уменьшается почти в 2 раза в течение уже первых 6 месяцев.

Для объяснения этих явлений образцы Na-CЦ с различным расположением замещенных групп в макромолекуле синтезированы методом избирательного сульфатирования и проанализированы методом термогравиметрии. Результаты показали, что все синтезированные образцы являются устойчивыми до $150{ }^{\circ} \mathrm{C}$ (рис. 1).

Изучение влияния расположения сернокислых групп в АГЕ на стабильность макромолекулы показало, что наиболее устойчивыми были образцы, содержащие в основном $\{\mathrm{C}-2\}$ замещенные группы среди монозамещенных и $\{\mathrm{C}-2,6\}$ среди дизамещенных производных. Самыми нестабильными являются образцы, имеющие замещенные сульфатные группы в основном в $\{\mathrm{C}-3\}$ положении (см. рис. 1).

В области 3700-3100 $\mathrm{cm}^{-1}$ ИК-спектра целлюлозы проявляются валентные колебания гидроксильных групп. Установлено, что внутримолекулярные водородные связи между гидроксильными группами в положениях $\mathrm{C}_{2}, \mathrm{C}_{6}$, равно как и в $\mathrm{C}_{3}$, образуются даже в присутствии следовых количеств гидроксильных групп (OH) [16]. Определено, что гидроксильные группы у третьего атома углерода не существуют в свободном состоянии, а образуют внутримолекулярные водородные связи с атомом кислорода глюкопиранозного кольца (рис. 3) [17]. Эти факты указывают на то, что замещение в свободных ОН-группах, которые принимают участие при образовании меж- и внутримолекулярных водородных связей, может увеличивать стабильность макромолекулы. Например, ОН-группы в С-3 и С-6 положениях принимают участие в создании водородных связей, и их полное замещение сернокислыми группами $\{\mathrm{C}-2,3,6\}$ делает макромолекулу более стабильной. Наоборот, в случае частичного замещения гидроксильных групп происходит отщепление эфирных групп в присутствии соседних транс-гидроксильных групп (при С-3 и С-6: $\{\mathrm{C}-3\}$, $\{\mathrm{C}-6\}$ и $\{\mathrm{C}-2,3\})$. В качестве доказательства мы сравнивали стабильности синтезированных Na-CЦ с дисульфатом полигалактуроната ( $\{\mathrm{C}-2,3-\mathrm{CПГК}\})$, чтобы проверить, насколько верно утверждение, что сернокислые группы гидролизуются при сульфатировании одной ОН-группы из трех и независимо от позиции заместителя в АГЕ. Результаты показали, что стабильность сульфатированных полигалактуронатов подобна $\{\mathrm{C}-2,3\}$ сульфатированным целлюлозам, и они являются более устойчивыми, чем однозамещенные производные сульфата целлюлозы (рис. 2).

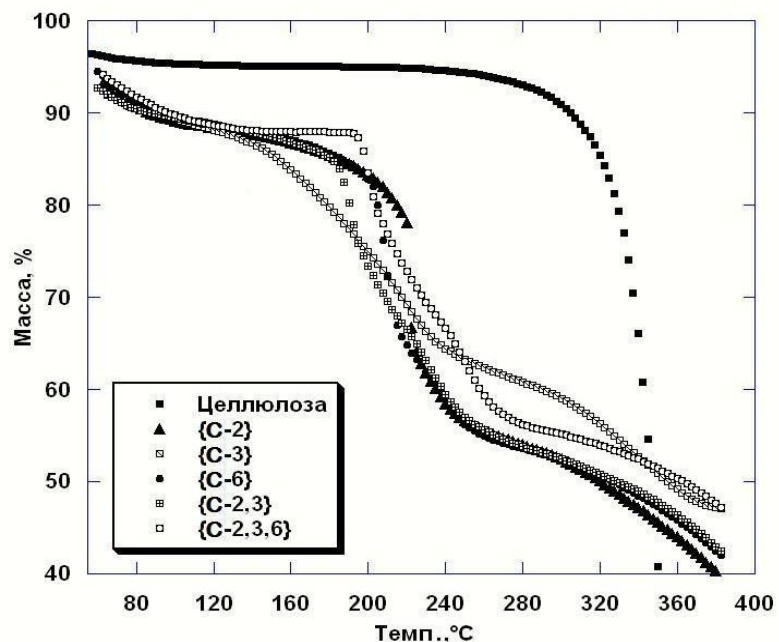

Рис. 1. ТГ анализ целлюлозы и сульфатпроизводных с различными местоположениями сульфатных групп

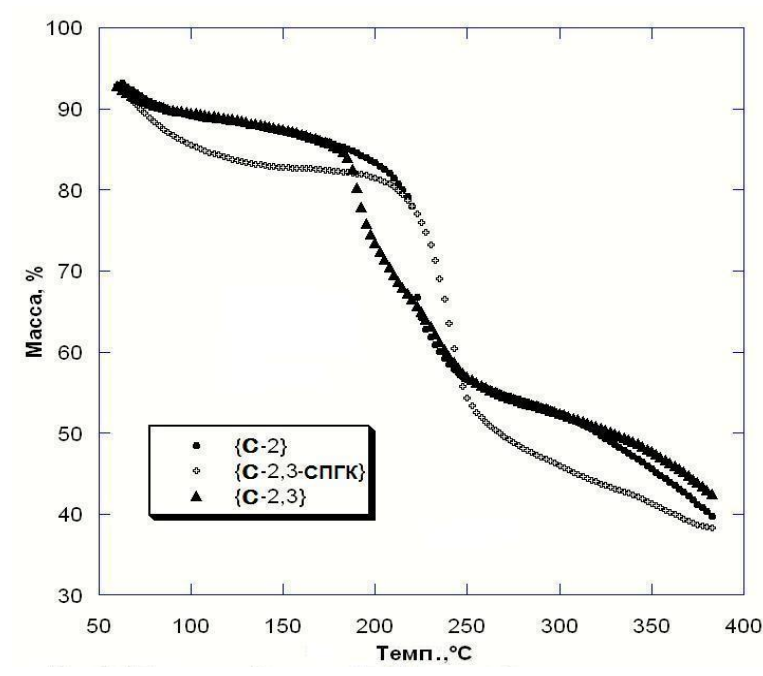

Рис. 2. ТГ анализ образцов Na-СЦ и сульфата полигалактуроната 


\section{Выводы}

На основе полученных результатов можно заключить, что меж- и внутримолекулярные водородные связи у сульфатированных полисахаридов оказывают решающее влияние на стабильность их сернокислых групп, гидроксильные группы в положении C-3 с большей вероятностью образуют этот тип связи в макромолекуле, если нет никакого замещения в других гидроксильных группах. Среди сульфатированных линейных полисахаридов высокозамещенные производные являются самыми устойчивыми, а образцы с большим замещением

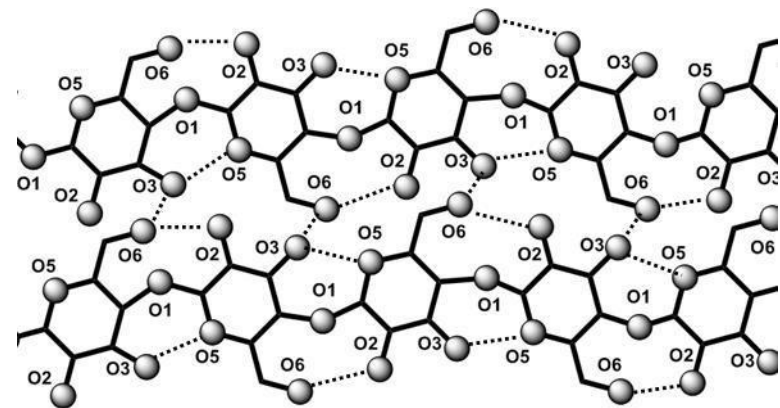

Рис. 3. Внутри- и межмолекулярные водородные связи целлюлозы при С-3 являются более лабильными.

\section{Благодарности}

Данные научные исследования выполнены в рамках проекта ФА-10-Т154 Центра по науке и технологиям при Кабинете министров Республики Узбекистан, а также при частичной финансовой поддержке программы DAAD, Германия. Авторы выражают особую благодарность проф. П. Мишнику (Брауншвайгский технический университет, Германия) за предоставленную методику и возможность экспериментальной работы по определению распределения замещенных групп в АГЕ у образцов.

\section{Список литературы}

1. Wang W.Z., Lin Li, Zheng B.Sh., Normakhamatov, N.S., Guo, S.Yu. Preparation and anticoagulation activity of sodium cellulose sulfate // Int J. Biol. Macromol. 2007. Vol. 41, N4. Pp. 376-382.

2. Местечкина Н.М., Щербухин В.Д. Сульфаты полисахаридов и их антикоагулянтная активность (обзор) // Прикладная биохимия и микробиология. 2010. Т. 46, №3. С. 291-298.

3. Patent 5679375 (USA). Method of treating ulcers with sulfated polysaccharides / C.A. Spilburg. 1997.

4. Brown G.D., Gordon S. Interferon induced polysaccharide compounds // Nature. 2001. Vol. 413. Pp. 36-37

5. Kučerová M., Pašteka M. Sulfation of cross-linked polysaccharides by the N,N-dimethylformamide-SO3 complex // Chemical Papers. 1975. Vol. 29, N5. Pp. 697-702.

6. Selwitz C. M. Cellulose Nitrate in Conservation. Research in Conservation 2. Chapp. 3. Causes of Instability. The Getty Conservation Institute, 1988.

7. Hyatt J.A. Acetylative desulfation of a glucose-6-sulfate: An oxygen isotope labelling study // Carbohydrates Research. 1993. Vol. 239. Pp. 291-296.

8. Heinze T. Esterification of Polysaccharides. Series: Springer Laboratory. 2006. 232 p.

9. Шелухина Н.П. Научные основы технологии пектина. Фрунзе. 1988. 32 с.

10. Аймухамедова Г.Б., Алиева Д.Э., Шелухина Н.П. Свойства и применение пектиновых сорбентов. Фрунзе, 1994. C. 61-62.

11. Normakhamatov N.S., Turaev A.S., Burkhanova N.D. Cellulose supramolecular structure changes during chemical activation and sulfation // Holzforschung. 2009. Vol. 63. Pp. 40-66.

12. Groth T., Wagenknecht W. Anticoagulant potential of regioselective derivatized cellulose // Biomaterials. 2001. Vol. 22. Pp. 2719-2729.

13. Klemm D., Philipp B., Heinze T., Heinze U., Wagenknecht W. Comprehensive Cellulose Chemistry. 1998. Vol. 2. $336 \mathrm{p}$.

14. Gohdes M., Mishnick P. Determination of the substitution pattern in the polymer chain of cellulose sulfates // Carbohydrates Research. 1998. Vol. 309. Pp. 109-115.

15. Percival E.G.V. Theoretical investigations of stabilities cellulosic esters with different degree of substitution // Quart. Rev. 1949. Vol. 3. P. 369.

16. Touey G., Gearhart W. Cellulose compounds // J. Chem. Eng. Date. 1961. Vol. 6, N4. Pp. 566-569.

17. Mike J. Chemistry: Cellulose stacks up // Nature. 2003. Vol. 426. Pp. 611-612.

Поступило в редакичию 18 февраля 2013 г. 
Normakhamatov N.S. ${ }^{*}$, Churkina K.M., Turaev A.S. INFLUENCE OF THE LOCATION OF SULPHATE GROUPS IN CELLULOSE SULPHATES ON STABILITY OF THEIR MACROMOLECULE

Institute of Bioorganic chemistry of the Uzbek Academy of Sciences, H. Abdullaeva, 83, Tashkent, 100125 (Uzbekistan), e-mail: ibchem@uzsci.net

Obtaining of sulfuric ester samples with various molecular parameters from cotton cellulose and influence of the location of sulphate groups in anhydroglucopyranose units on their stability were presented in the article. The changes of molecular characteristics took place during one year storage of aqueous solution of the samples and thermo-gravimetrical analyses of their dry form have been studied. The results showed the samples with highly substitution degree by sulfate groups were more stable and most samples with substituted groups in $3^{\text {rd }} \mathrm{OH}$-position showed the weakest stability. It was assumed that the nonsubstituted trans- hydroxyl groups in the anhydroglucopyranose unit could supposedly be responsible for the instability.

Keywords: sodium cellulose sulfate, location of the substituted patterns, macromolecular stability, thermogravimetry.

\section{References}

1. Wang W.Z., Lin Li, Zheng, B.Sh., Normakhamatov, N.S., Guo, S.Yu. Int J. Biol. Macromol., 2007, vol. 41, no. 4, pp. 376-382.

2. Mestechkina N.M., Shherbuhin V.D. Prikladnaja biohimija i mikrobiologija, 2010, vol. 46, no. 3, pp. 291-298. (in Russ.).

3. Patent 5679375 (USA). 1997.

4. Brown G.D., Gordon S. Nature, 2001, vol. 413, pp. 36-37.

5. Kučerová M., Pašteka M. Chemical Papers, 1975, vol. 29, no. 5, pp. 697-702.

6. Selwitz C. M. Cellulose Nitrate in Conservation. Research in Conservation 2. Chapp. 3. Causes of Instability. The Getty Conservation Institute, 1988.

7. Hyatt J.A. Carbohydrates Research, 1993, vol. 239, pp. 291-296.

8. Heinze T. Esterification of Polysaccharides. Series: Springer Laboratory. 2006. 232 p.

9. Sheluhina N.P. Nauchnye osnovy tehnologii pektina. [Scientific basis of the technology of pectin]. Frunze, 1988, 32 p. (in Russ.).

10. Ajmuhamedova G.B., Alieva D.Je., Sheluhina N.P. Svojstva i primenenie pektinovyh sorbentov. [Properties and application of pectin sorbents.]. Frunze, 1994, pp. 61-62. (in Russ.).

11. Normakhamatov N.S., Turaev A.S., Burkhanova N.D. Holzforschung, 2009, vol. 63, pp. 40-66.

12. Groth T., Wagenknecht W. Biomaterials, 2001, vol. 22, pp. 2719-2729.

13. Klemm D., Philipp B., Heinze T., Heinze U., Wagenknecht W. Comprehensive Cellulose Chemistry, 1998, vol. 2, $336 \mathrm{p}$.

14. Gohdes M., Mishnick P. Carbohydrates Research, 1998, vol. 309, pp. 109-115.

15. Percival E.G.V. Quart. Rev., 1949, vol. 3, p. 369.

16. Touey G., Gearhart W. J. Chem. Eng. Date, 1961, vol. 6, no. 4, pp. 566-569.

17. Mike J. Nature, 2003, vol. 426, pp. 611-612.

Received February 18, 2013

Revised November 13, 2013

\footnotetext{
* Corresponding author.
} 